\title{
On the Aesthetic Characteristics and Cultural Analysis of Chinese IP film
}

\author{
Jing Li
}

School of Chinese Language and Literature, Jinan University, Guangzhou 510632, China.

\begin{abstract}
Keywords: IP film, aesthetic, cultural analysis.
\end{abstract}
\begin{abstract}
Domestic IP film has a strong influence in the domestic box office market. Reliance on fan base, resulting in domestic IP film cater for the mass consumer and the greatest degree of expansion, extrusion great aesthetic quality of art like Profit doctrine as its salient features, it' s cultural quality is worrisome. Under the policy background of cultural soft power competition and the "going out" of Chinese culture, domestic IP film's cultural significance needs attention and strengthened, so as to serve China's cultural development.
\end{abstract}

\section{Introduction}

Needless to say, in recent years, the box office performance has fully confirmed strong influence of the IP film in the domestic market.Since 2013, Almost every year many IP films become the domestic box office top ten,and almost swept the top three box office ranking list. On the one hand, we should pay attention to Ip film' s economic / box office effect; On the other hand, the economy / box office effect should not be the only concern of the IP film,after all, as spiritual product, in addition to the economy effect, the film need to carry the cultural functions of production and dissemination .Especially for the current hot high box office IP film, its huge fans not only ensure its high box office, but also provides a positive platform of culture and spirit.At present, the situation is worried, the domestic high box office IP film culture transmission has many problems, it is not satisfactory.

\section{Organization of the Text}

The Internet has become the infrastructure of social operation, Its impact on tradition is not limited to one side, but constitutes a thorough reconstruction force. It has been deeply involved in social politics, economy and culture.In the present interconnection of the times,as a form of cultural presentations,the film naturally can not escape the shape of the era and "immune."Internet intervention in the film is a natural thing.IP film is cultural form of the "media integration" between traditional media and Internet new media.

IP is the English abbreviation of "Intellectual Property" , meaning "intellectual property".But film and television industry recently referred to the IP, is not limited to the original intention in English.The earliest use of IP is in the field of the game in 2013, refers to the video adaptation of the game.It entered the film and television industry, and Internet companies layout content industry, the implementation of pan-entertainment ecosystem strategy is directly related.Tencent in September 2014, the landmark event is "Tencent movie + Star IP" program, a total of seven well-known IP was gradually adapted into a movie.The following year, IP was widely talked about into the public view, and gradually extended from the game industry to animation, film and television, derivatives, literature and other fields[1].

Domestic IP film, the earliest dating back to the novel under the same name network adaptation is " First intimate contact", Of course, there is no concept of IP film, but in accordance with the current IP film, which is a standard IP film,After the "Go Lala Go!", "Love is not blind", "You are apple of my eye", "So Young" and so on,To 2014, as an industry hot words,IP films got the major film companies and spectators competing in the pursuit, Then launched the "Fleet of Time", "pancake 
Man", "Surprise", "Mojin - The Lost Legend", "You are my sunshine", "The left ear", "Chronicles of the ghostly tribe " and other works,these films were caused great attention, and eventually got very high box office.For a moment, IP films were very popular.

As a medium for the production of movies and the Internet, IP films still retain the general standard of the film, their output and production, distribution and screening are not different from non-IP movies, In IP film features of the Internet is mainly reflected in the material source, the fans base and the style type.First of all, IP films are drawn from the Internet,Such as "Love is not blind" adapted from Bao Jingjing' s post(pompon) on the Douban,You are my sunshine"and "Mojin - The Lost Legend" adapted from the network novel, "Surprise"and "pancake Man" adapted from the Internet, "One Hundred Thousand Bad Jokes" adapted from the network cartoons and so on,Internet provides IP movie rich content resources.Second, the Internet not only provides content resources, but also provides a huge fan audience base for the IP film.IP in the IP movie is often high-quality IP, which has already attracted large groups of fans on the Internet,Therefore, before the release,these high-quality IP in the IP films has obtained a high popularity and attention,With the release of the film, a huge fan base is converted to the audience, which provide the basis for IP film box office protection.Third, IP film's Internet features limited the IP movie style type to a certain extent. The Internet has the cultural characteristics of popular carnival,So the youth culture-based Internet products have the characteristics of low threshold and strong consumption,Internet culture is a typical flat culture, which seriously lack of cultural depth,it also caused IP film corresponding cultural characteristics, Objectively speaking,in the past two years, although the IP movie is very popular, but the real fine film is scarce.

The last two years,because the domestic IP films have the strong box office performance in the domestic film market, all kinds of commercial capital intensively focus on film industry.Given the proximity of IP film and the internet, as represented by BAT Internet Corpration have entered the film industry, and laid out the film industry chain, and stressed the development of IP entertainment.BAT's time to enter the film industry is almost synchronized with the IP film:In June 2014, Ali pictures was established; in July of the same year, Baidu's Iqiyi has also set up a special film company;At the beginning of 2015, Baidu has quietly established Baidu pictures. In September 2015, Tencent has announced the establishment of two film company, Penguin pictures and film Tencent.The penguin pictures based on Tencent video,focused on the network drama and film investment; The Tencent is based on mutual entertainment studios Tencent, mainly focus on literature, animation film adaptation of IP.In addition to BAT, the real estate started Wanda Group also involved in film and television, it not only has their own film and Television Company Wanda film, but also widely expand overseas business,In January this year, Wanda Group invested \$3 billion 500 million buy American independent film production company legendary pictures, what is the value of the high quality IP strong accumulation and derivative ability.

For the strength of the commercial capital stationed in the film industry, we can assess from two aspects.On the one hand, the parties of commercial capital has greatly promoted the rapid development of the domestic film industry.Since the new century, the domestic film market take nearly 10 years to break through ten billion,But since 2013, it rapidly progress: 2013 box office revenue exceeded twenty billion, the final reached 21 billion 700 million, growing at $27 \%$, the total box office in 2014 reached 29 billion 600 million,growing at 36\%, in 2015 annual total box office reached 44 billion,growing at 48\%,Chinese film market has certainly become the world's second largest film market,market capitalization after the North American market, So the presence and contribution of strong commercial capital can not be ignored. On the other hand,although the commercial capital push up the domestic film market, due to the consumption characteristics of capital profit too much emphasis on the film ' consumption,also directly or indirectly lower the quality of domestic film art, it is also a fact. 
The fans make Domestic IP film earn high box office, a very large number of fans of the audience hold IP movie box office;But at the same time, it also caused the risk of IP movie replacement for fans of the film, When the IP film place the planning and production on the group of fans, its popularity and consumption is bound to be the greatest degree of expansion, while greatly squeezing the aesthetic quality of the arts and so on,So, we can see that popularity and consumption even become a lot of domestic high box office IP movies only demands.

Because of the irrational pursuit of fans, Although the domestic IP film in the domestic market even doesn' t "carved",but it can still earn much money,so it cause the domestic IP movie extremely caters to the tendency of the fans,from planning to creation, marketing, followed by the consumption of capital and profit model, rather than the main pursuit of the film art.So, in the non film production mode to launch domestic IP film, the consumer shows and art of weak, self is reasonable.Therefore, if we use "non-film" mode product domestic IP film, we will inevitably highlight its consumption and and weaken its art.

Commercial and artistic departure reflect serious dislocation of the mainland and overseas box office in the domestic IP film.In the mainland market, with the help of rampant wave of fans culture, IP film is popular, so domestic IP film can easily take hundreds of millions money at the box office;However, in the North American market, which focuses on the artistic quality of foreign language films, IP movies are not competitive because of the lack of artistry.In 2015, 9 domestic high-ticket IP film 11 billion yuan account for the total annual box office value of 1/4,And 2013-2015 three-year North American issue of 17 domestic high-ticket box office IP film north American box office total is less than 700 million US dollars at the box office data, it is very embarrassing and worrying. if things go on like this,the domestic film will be heavily dependent on the mainland market, and form "inward look" conservative tendencies.Just think, when the domestic IP film can earn much money in the Mainland market without "carved", who would care about the very few overseas markets?At the same time, the profitability of domestic IP film will be amplified in the short term, which form a demonstration in the mainland film market, IP is more sought after, the production is more rough,As long as it is good quality IP, which have fan base , no matter how rough the film was made,it still able to obtain box office success.In this way, domestic films will fall into a vicious circle, the quality of the arts will get worse.

The last two years, although domestic IP film in the mainland market has made a great box office success,but we must realize the success has a certain "moisture", because it is not completely liberalized in the domestic film market protection environment to obtain, it is the competition in the non-saturated "greenhouse" to be achieved.In 2012,in Los Angeles,China signed "China and the United States on the WTO film-related issues to resolve the Memorandum of Understanding" on the current quota system,this Agreement is valid for five years, which means that the two sides will carry out the second round of negotiations in February17.2017.In this negotiation, China's import quotas will inevitably increase.Hollywood's goal is not china film market "further open", but "completely open". Once the mainland film market fully liberalized, facing Hollywood as the representative of the positive impact of overseas films, domestic films will face great pressure to survive.Seriously rely on the mainland market, the domestic film has basically lost the competitiveness of overseas markets.If we can not seize the current protection period "window", we still profit by shoddy, once lose the mainland market in the saturated competition, it will be a disaster for our cultural security[2].

In recent years, the Chinese film market is developing at a high speed, the commercial capital of all parties are firmly focused on the film industry. IP movies have become the best bridge for communication between commercial capital and the film industry.IP film has the audience base, box office protection, potential profit ,the pursuit of profit is the nature of capital,so most of the current popular IP movies are dominated by commercial investment,the production process of the IP film is controlled by the commercial capital, not the film people,How to shoot the film is determined by the 
fine business calculus, the film is only responsible for the profitability of the capital, the film's artistic quality is only in the second.

\section{Summary}

Domestic IP film has a strong influence in the domestic box office market. Reliance on fan base, resulting in domestic IP film cater for the mass consumer and the greatest degree of expansion, extrusion great aesthetic quality of art like Profit doctrine as its salient features, it' s cultural quality is worrisome. Under the policy background of cultural soft power competition and the "going out" of Chinese culture, domestic IP film's cultural significance needs attention and strengthened, so as to serve China's cultural development.

As a kind of artistic form, the film's sound and picture has the coherence, compared to literature and other media art,it has the convenience of cross-cultural communication.In the present to promote cultural "going out" policy context, the domestic film should assume greater cultural responsibility.But the reality is the contrary, in recent years, due to the rise of IP movies, domestic films did not revive the glory of the international cross-cultural transmission in the nineties of last century and the new century, but become more rough and more embarrassment in the profit-driven greed, overseas competitiveness is almost zero, the abnormal trend also indicates new crisis in the mainland market.

Under the control of capital, the domestic IP film has the cultural tendency of "utilitarianism", if uncontrolled and further developed,it will seriously squeeze the living space of the other film types which focus on the artistic nature in the mainland film market, thus bringing the great risk for the national ideology and cultural security. In this regard, we must maintain sufficient awareness and vigilance.

\section{References}

[1] Information on http://mt.sohu.com/20160411/n443902708.shtml

[2] Information on http://www.kekegold.com/yule/star/3173.html 